Aim The aim of this study was to establish if the anti-epileptic effect of Mozart music on EEGs is present in children.

Methods Forty five children aged 0-18 with EEGs showing epileptiform activity were included in the study. They were selected opportunistically, from those attending for routine EEG analysis who had epileptic EEGs. Mozart's Sonata for two pianos in D major (K448) and an age-appropriate control music were used. Epileptic EEG activity was measured in five states, each lasting 5 minutes; before Mozart music (baseline), during Mozart music, after Mozart music/before control music, during control music and after control music. The results were analysed manually.

Results A significant reduction $(p<0.0005)$ in the frequency of epileptic discharges was found during listening to the Mozart music compared to the baseline. No significant difference was found between the baseline and the other three states. No significant difference was found between during listening to the Mozart music and during listening to the control music.

Conclusion This study confirms an anti-epileptic effect of Mozart music on EEG activity in children, with a significant reduction in the frequency of epileptic discharges during listening to the Mozart music compared to the baseline, which was not present when listening to the control music. This study warrants further investigation into whether this effect could be achieved with other similarly structured music to Mozart. It opens doors to investigation into the long-term use as a therapy for epilepsy and to enhance understanding of epileptogenesis. Given the large proportion of children suffering from refractory epilepsy and the financial burden of epilepsy medication, a new therapy would be welcomed.

\section{G192 THE USE OF FAECAL CALPROTECTIN IN PAEDIATRIC INFLAMMATORY BOWEL DISEASE}

doi:10.1136/archdischild-2013-304107.204

1JR O'Gorman, ${ }^{2} S$ Hussey, ${ }^{3 R K}$ Russell. 'School of Medicine, University of Glasgow, Glasgow, UK; 'Department of Paediatric Gastroenterology, Our Lady's Children's Hospital, Dublin, Ireland; '3epartment of Paediatric Gastroenterology, Royal Hospital for sick Children, Glasgow, UK

Aims To evaluate the use of faecal calprotectin (FC) in children with suspected inflammatory bowel disease (IBD) in the previous year, and to establish if the number of negative endoscopies had been minimised without missing any cases of IBD. To assess the use of FC in established paediatric IBD. To analyse the cost benefit of the test.

Methods A retrospective analysis of FC measurements carried out between $1^{\text {st }}$ October 2011 and $30^{\text {th }}$ September 2012. FC measurements were obtained from the biochemistry department. Following a computerised search of the departmental records the presenting complaint, endoscopy result if applicable, diagnosis of IBD or alternative diagnosis, and follow-up or discharge were recorded for each patient. Patients were divided into those who were scoped based on their FC value and those who were not. Established IBD patients who had a FC test as part of their disease management were treated as a separate group.

Results 36 patients (55\%) were not scoped. All 36 had at least one symptom indicative of IBD. 25 of these had a FC value of $<50 \mu \mathrm{g} / \mathrm{g}$. 4 of these patients had a FC result $>200 \mu \mathrm{g} / \mathrm{g}$. None of these patients have been diagnosed with IBD. 17 patients were scoped (26\%). 3 of these patients were diagnosed with IBD. Median FC for the group that were not scoped was $30 \mu \mathrm{g} / \mathrm{g}$ (interquartile range (IOR) $30-760 \mu \mathrm{g} / \mathrm{g}$ ), compared with $126 \mu \mathrm{g} / \mathrm{g}$ (IOR $52-1,590 \mu \mathrm{g} / \mathrm{g}$ ) in the group that were scoped. 8 patients with known IBD had a FC test when they became symptomatic and all FC values were consistent with GI inflammation. Overall, there was a $38 \%$ cost saving due to 44 unnecessary endoscopies being avoided.
Conclusion FC is a valuable test for excluding IBD in patients who present with abdominal pain and diarrhoea. FC can confirm relapse in symptomatic patients known to have IBD. When the test is used in these ways patients avoid an invasive procedure and the hospital is saved the cost of the endoscopy. However, guidelines are required to ensure the correct and appropriate use of this relatively new test.

\section{G193 THE ROLE OF ACUTE RESPIRATORY EVENTS IN CHILD DEATHS DUE TO NEUROLOGICAL CONDITIONS AND CONGENITAL ANOMALIES}

doi:10.1136/archdischild-2013-304107.205

J Davey, P Hardelid, N Dattani, R Gilbert. MRC Centre of Epidemiology for Child Health, UCL, London, UK

Aims To determine the role of acute respiratory events mentioned on death certificates of children dying of a neurological condition or a congenital anomaly in the UK.

Methods Data on causes of death, extracted from death certificates from 11262 children who died between 2006 and 2010 aged one to 18 years, were obtained from national statistics agencies in England and Wales, Scotland and Northern Ireland. We scrutinised all causes of death for children whose underlying cause was a neurological/perinatal condition or a congenital anomaly to determine whether an acute respiratory event had occurred. An acute respiratory event was defined as acute upper and lower respiratory tract infections and acute respiratory failure. The proportion of children whose death certificate mentioned an acute respiratory event was estimated overall and by age-group (1-4, 5-9, 10-14 and 15-18 years).

Results 1433 children died from a neurological/perinatal condition and 867 children died from a congenital anomaly in the study period, representing $12.7 \%$ and $7.7 \%$ of all deaths. Among children dying of a neurological/perinatal condition, 470 (32.8\%) death certificates mentioned an acute respiratory event. The prevalence of acute respiratory events varied by age, from 78/470 (16.6\%) in $5-9$ year olds to $154 / 470$ (32.8\%) in 1-4 year olds. Among children dying of a congenital anomaly, 201 death certificates mentioned an acute respiratory event (23.2\%). Prevalence ranged from 29/201 (14.4\%) in 10-14 year olds to 99/201 (49.3\%) in 1-4 year olds. Overall, the most common acute respiratory events were unspecified pneumonia, recorded on $11.7 \%$ of death certificates (268 of 2300), unspecified bronchopneumonia, recorded on 10\% (228 of 2300) and unspecified respiratory failure recorded on $9.3 \%$ (214 of 2300).

Conclusions Acute respiratory events are common contributing causes of death among children dying from neurological/perinatal conditions or congenital anomalies. Such events may represent a failure of chronic care or be part of an expected, planned death. Further research is needed to determine how to distinguish between these pathways of care.

\section{G194 A 15-YEAR REVIEW OF OPEN VERSUS LAPAROSCOPIC BOIX-OCHOA FUNDOPLICATION}

doi:10.1136/archdischild-2013-304107.206

'BN Ertansel, ${ }^{2} \mathrm{SD}$ Adams, ${ }^{2} \mathrm{CJ}$ Healy, ${ }^{2} \mathrm{SC}$ Blackburn, ${ }^{2} \mathrm{AAE}$ van der Avoirt. ${ }^{1}$ Faculty of Medicine, Brighton \& Sussex Medical School, Brighton, UK; ${ }^{2}$ Paediatric Surgery, Royal Alexandra Children's Hospital, Royal Sussex County Hospital, Brighton, UK

Aim Boix-Ochoa Fundoplication is a established surgical treatment for gastroesophageal reflux disease. The surgical outcomes of this procedure have been compared to other types of Fundoplication in literature. There is no current publication comparing open to laparoscopic Boix-Ochoa Fundoplication. The aim of this study is to compare the outcomes of open versus laparoscopic Boix-Ochoa Fundoplication. 